\title{
Research on Multi-Subject Incentive Cooperation of College Students' Network Entrepreneurial Education
}

\author{
Zhang Zhe \\ JIYang College of Zhejiang A\&F University \\ Zhuji City, China \\ zhangyqmine@163.com
}

\author{
Zhou Xi \\ JIYang College of Zhejiang A\&F University \\ Zhuji City, China \\ 137116128@qq.com
}

\begin{abstract}
The aim of this study was to discuss the Incentive Mechanism of the Cooperation among the government, enterprise and college so as to promote the development of College Students' Network Entrepreneurial education. We analyze the interest demands and cooperation mechanism of each subject in the process of Network Entrepreneurial Education for College Students. And a mutual incentive model is proposed. By means of derivation, we conclude that the incentive of the government is greater when the unit cost of the government encouraging enterprises to cultivate entrepreneurial teams is lower and the value created by the entrepreneurial teams is higher. And enterprises can obtain an incentive when the marginal revenue of human capital and other factors required for maximum profit is equal to the respective unit cost and the combination of demand factors in cultivating entrepreneurial teams achieves the best proportion. And universities can obtain the incentive when the coefficient of college benefits and enterprise incentive reach maximum.
\end{abstract}

Keywords-College Students' Network Entrepreneurial Education; collaboration; incentive model; government; enterprise; University

\section{INTRODUCTION}

According to research reports from the status of China youth entrepreneurship, the number of domestic college students' entrepreneurship is $12.6 \%$ of the total number of college students, and more are inclined to e-commerce venture (also known as "network business"). Entrepreneurial education on the network is a new and important job being carried out in colleges and universities. Practice shows that the cooperation between universities and government, between universities and enterprises is usually on the surface, and its progress is slow or even aborted, exerting adverse influences on the government, enterprises, and universities and so on. Literature research shows that most of the existing researches emphasize how to encourage enterprises to participate in the university-industry cooperation, but ignore incentive researches of two main bodies: the government and universities. This paper discusses the establishment of multi-subject cooperation mechanism and incentive model of College Students' Network Entrepreneurial Education among the government, enterprises and colleges,

The work was fully supported by funds from key teaching reform projects (number: TMZD1302) of JIYang College of Zhejiang A\&F University and The Research Project of Human Resources and Social Security in Zhejiang Province (Name: Research on the Cultivation Mechanism of Agriculturally Highly Skilled Talents in the Perspective of Cooperative Innovation) which is designed to promote the healthy and rapid development of College Students' Network Entrepreneurial education.

\section{Summary of Interest Demands of EACH SUbJeCt IN THE PROCESS OF NETWORK ENTREPRENEURIAL EDUCATION FOR COLLEGE STUDENTS}

In the network entrepreneurial education based on the multi-subject collaboration, the local government, enterprises, universities and other subjects have their own interests. As far as the local government is concerned, to accelerate the development of local real economy, it expects enterprises and universities to cooperate comprehensively in its policy guidance and encouragement, combined with the characteristics of contemporary college students' entrepreneurship, constantly improving regional development level of enterprise e-commerce, so as to realize economic benefits and goals of the government. Under the environment of Internet, enterprises are facing transformation and upgrading, with an urgent need to obtain talents of network technology applications and innovation capabilities, e-commerce applications. Through the full integration of government, enterprises and other advantages of resources, colleges make efforts to build a platform of network of theory and practice in college students' entrepreneurial education, cultivate College Students' entrepreneurial talents of high quality, in order to improve their reputation in the industry and society.

\section{ANALYSIS OF COOPERATION MECHANISM OF COLLEGE STUDENTS' NETWORK ENTREPRENEURIAL EDUCATION}

\section{A. Use of policies by the government to drive further cooperation between enterprises and universities}

Innovation is the driving force of economic development under the new normal, and colleges and universities have always been one of the main forces of scientific and technological innovation, giving energy to local economic transformation and development. The local government tries to promote the development of local economy through the cooperation with universities, incorporating the local college students' entrepreneurial education into the government's economic and social development plan, carrying out a series of preferential policies to encourage enterprises to participate and 
support university students' network entrepreneurial education. It is a good way to encourage enterprises and universities fully cooperate, provide manpower, finance, material and technology resources for college students' network entrepreneurial education, and ultimately enhance the quality level of college students' network entrepreneurial education.

\section{B. Colleges' building of students' network entrepreneurial teams with the help of enterprises}

Practice shows that the threshold of the success of the network business is pretty high. It needs to be carefully nurtured, so the guidance of college internal guidance teachers is far from enough. Under incentives of the government policy, enterprises, focusing on the long-term interests, through the establishment of cooperation relationship with universities, help colleges with the selection of college students' network entrepreneurial teams and entrepreneurial projects, providing entrepreneurial guidance for college students' network entrepreneurship, teaching college students' entrepreneurial team business management, e-commerce and other knowledge and skills, and forming a partnership with the college students' network entrepreneurial team, so as to avoid the abortion of college students' network entrepreneurial team aborted and promote the incubation of college students' network entrepreneurial team.

\section{Full integration of government and enterprise high-quality resources to cultivate high-quality college students' entrepreneurial teams by colleges}

Universities actively cooperate with local governments, enterprises, putting the high-quality resources of the government and enterprises into the use of college students' network entrepreneurship education. Firstly, colleges strive from the government all policies in favor of the entrepreneurship of college students; secondly, establish leadership groups of college students' network entrepreneurial education together with the government and enterprises, overall planning and coordinating various resources; thirdly, establish curriculum systems of college students' network entrepreneurial education with enterprises and carry out relevant management plans to encourage senior business people to come to the campus, and classrooms, be college students' entrepreneurial mentors, teach innovation and entrepreneurial spirit and share entrepreneurial experience.

\section{InCENTIVE MOdEL OF Multi-SubJeCt COOPERATION IN COLLEGE STUdENTS’ NETWORK ENTREPRENEURSHIP EDUCATION}

In conclusion, whether the government can introduce incentive policies of cooperation between universities and enterprises, and maintain efficient and sustainable policies; whether the enterprises are willing to assist in incubating business teams; whether universities are willing to spend time and energy building network entrepreneurial education for college students only with the objectives being encouraged can the ideal goal be achieved.

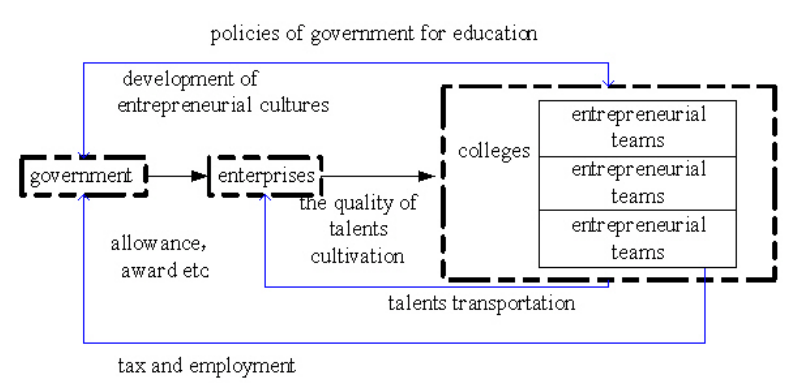

Fig. 1. Mutual incentive model of multi-subject cooperation

\section{A. The incentive model of government participation in the network entrepreneurship education of college students}

Government is an important institutional arrangement [1] to realize national economic and social development, social justice and social value. Government performance evaluation is the tool [2] of evaluating government performance and efficiency. To achieve better performance, the local governments take all possible measures to promote local economic growth, increase revenue, and expand employment [3]. In picture 1 , in the process of multi-subject cooperation of college students' network entrepreneurial education, government revenue mainly comes from entrepreneurial teams in Colleges and universities, which means that entrepreneurial teams create new jobs for society, pay taxes to the local government and the colleges and universities directly deliver talents of network entrepreneurship and employment o the local economic development. And through students' network entrepreneurship, it leads to more local people to be engaged in network business, creating a good business atmosphere for the whole society and promoting the development of local entrepreneurial culture. Research shows that entrepreneurial activities can generate new jobs directly through the expansion of production capacity [4]. In our country, entrepreneurial activities can make a great impact on the increase of employment, and innovative entrepreneurial activities also have a great impact on regional economic growth [5][6]. Therefore, the local government may introduce preferential policies to guide enterprises and universities to reach the cooperation of college students' network entrepreneurial education, promote enterprises to cultivate entrepreneurial teams, through which the local government can obtain GDP growth and employment increase, etc. in government performance. Because the impact of entrepreneurial teams has a certain lag, this paper assumes that entrepreneurial teams in the analysis are successful and based on this assumption, the relevant incentive model of government's participation is introduced.

Assuming that the obtainable government performance is $Q 1$, and the number of entrepreneurial teams developed by enterprises is L1, then the government performance function can be seen as a function of the number of entrepreneurial teams. Then:

$$
Q_{1}=Q_{1}\left(L_{1}\right)
$$


Assuming that the reputation and performance raised by government's promotion of an entrepreneurial team is $M P$, then:

$$
M P=\frac{d Q_{1}\left(L_{1}\right)}{d L_{1}}
$$

Assuming that the government encourages enterprises to cultivate an entrepreneurial team, the GDP created by the entrepreneurial team itself is $P_{1}, M P \cdot P_{1}$ means the increased value of GDP by increasing a business team, and marginal revenue of entrepreneurial teams cultivated by enterprises and encouraged by the government is $V M P$, then:

$$
V M P=M P \cdot P_{1}
$$

The government's encouragement of enterprises cultivating entrepreneurial teams, needs to pay rewards, preferential policies and other costs, so assuming the cost of the government as $C_{1}$. This cost function expresses relationships between the cost of the government and the performance level obtained, or in short, cost is only seen as a function of government performance evaluation, then:

$$
C_{1}=C_{1}\left(Q_{1}\right)
$$

Assuming that the cost for the government to foster an entrepreneurial team is $W_{1}$, then the cost function of the government's promoting enterprise entities can also be expressed as:

$$
C_{1}=W_{1} \cdot L_{1}
$$

In formula (5), $W_{1}$ is an unchangeable constant, so the marginal cost of enterprises encouraged by the government is the derivative of cost function to the entrepreneurial team number, then:

$$
\frac{d C_{1}\left(L_{1}\right)}{d L_{1}}=W_{1}
$$

When the marginal cost of the government urging enterprises to cultivate the entrepreneurial teams is equal to the corresponding marginal revenue, the government reputation, performance and other government performance evaluation achieve the optimal equilibrium state. The marginal revenue of the government urging enterprises to cultivate entrepreneurial teams is VMP and marginal cost is $W_{1}$, then:

$$
V M P=W_{1}
$$

$$
M P \cdot P_{1}=W_{1}
$$

Meet the needs of formula (8) is the prerequisite of government performance evaluation in achieving an optimal equilibrium state. Formula (8) shows that for the government of encouraging enterprises to cultivate entrepreneurial teams, there is a best number combination between the number of entrepreneurial teams and performance obtained. The number of training entrepreneurial team is 0 at the beginning, and with the increase in the number of training entrepreneurial teams, the government obtains more marginal performance, and finally reaches the maximum. At this time, with the increase of entrepreneurial teams, the number of training quantity goes astray from the best combination ratio, and the corresponding marginal amount declines.

From the above analysis, the performance function increases with the increase in the number of government's promoting enterprises to cultivate entrepreneurial teams. When the number increases to a degree, the performance decreases with the increase of training entrepreneurial teams, which fits the quadratic function with down openings. Because $L_{1} \geq 0$, the symmetric axis of the quadratic function is greater than 0 .

Assuming that the function of performance evaluation is

$$
Q_{2}=-k_{1} L_{1}^{2}+k_{2} L_{1}+G
$$

Among which, $k_{1}, k_{2}>0, G$ is a constant.

From the formula (2) and (8), there is:

$$
W_{1}=M P \cdot P_{1}=\frac{d Q_{2}\left(L_{1}\right)}{d L_{1}} \cdot P_{1}
$$

From the formula (9) and (10), there is:

$$
W_{1}=\left(-2 k_{1} L_{1}+k_{2}\right) \cdot P_{1}
$$

From the formula (11), there is:

$$
\frac{-2 k_{1} L_{1} P_{1}}{-2 k_{1} P_{1}}=\frac{W_{1}-k_{2} P_{1}}{-2 k_{1} P_{1}}
$$

At this time, the optimal number of training entrepreneurial team in the optimal equilibrium state is

$$
L_{1}=\frac{k_{2}}{2 k_{1}}-\frac{W_{1}}{2 k_{1} P_{1}}
$$

From the formula (11), there is:

Put formula (3) into (7), then: 


$$
\begin{gathered}
\partial L_{1} / \partial W_{1}=-\frac{1}{2 k_{1} P_{1}}<0 \\
\partial L_{1} / \partial P_{1}=\frac{W_{1}}{2 k_{1} P_{1}^{2}}>0
\end{gathered}
$$

From the formula (14), (15), it shows that the performance obtained by the government grows in inverse proportion to unit cost of the government's promoting enterprises to cultivate entrepreneurial teams, and grows in direct proportion to the value created by training entrepreneurial teams. So when the lower the unit cost of the government's promoting enterprises to cultivate entrepreneurial teams is, and the higher the value created by entrepreneurial teams is, the incentive gained by the government is greater.

\section{B. The optimal incentive model of enterprises participating in the College Students' Network Entrepreneurship \\ Education}

Enterprises play a decisive role in the process of multisubject cooperation of College Students' Network Entrepreneurship Education. Under the condition of market economy, costs and benefits are the most important factors in enterprise's decision-making. Although the government hopes that the policy of subsidies, incentives and other financial means can encourage enterprises to take the initiative to carry out cooperation with colleges and universities, to improve enterprise performance promote the development of electronic commerce and local economic growth of the local enterprises [7], whether the company will cater the government policy depends on the amount obtained in the cooperation with universities. As is shown in Fig.1, corporate profits are mainly from the government and universities, that is, the government's subsidies, incentives and universities' e-commerce talent transportation to enterprises, income brought by entrepreneurial teams, corporate reputation, etc.

In the process of cooperation, enterprises should be required to cultivate students' entrepreneurial teams. Assuming that the number of entrepreneurial teams needed to cultivated by universities is $Q_{3}$, at this time the human input of the enterprise is ${ }_{L}$, the amount of capital input is ${ }_{K}$, then the demand function of the training is

$$
Q_{3}=f(L, K)
$$

Assuming that the income of enterprise collaboration cultivating a single venture team is $Y$, in which this part of income includes two parts: government subsidies and rewards, benefits brought by entrepreneurial teams to the enterprise. Per unit cost of the enterprise human resources input is $w$, and the unit cost of capital investment for the cultivation of collaboration is $v$, so for enterprises profits can be obtained are:

$$
\pi(L, K)=Y Q_{3}-(w L+v K)=Y \cdot f(L, K)-w L-v K
$$

From formula (17), the first order condition of the enterprise profit maximization is:

$$
\begin{aligned}
& \frac{\partial \pi}{\partial L}=\frac{\partial f}{\partial L}-w=0 \\
& \frac{\partial \pi}{\partial K}=\frac{\partial f}{\partial K}-v=0
\end{aligned}
$$

From formula (18)-(19), there is:

$$
\begin{aligned}
& \frac{\partial f}{\partial L}=w \\
& \frac{\partial f}{\partial K}=v
\end{aligned}
$$

From formula $(20) /(21)$, there is:

$$
\frac{\partial f}{\partial L} / \frac{\partial f}{\partial K}=\frac{M Y_{L}}{M Y_{K}}=\frac{w}{v}
$$

So the first order condition of the enterprise profit maximization is:

$$
\frac{M Y_{L}}{M Y_{K}}=\frac{w}{v}
$$

In the pursuit of profit maximization, we can get the optimal combination of second order conditions of the cooperative training demand factors:

$$
\begin{aligned}
& \frac{\partial^{2} \pi}{\partial L^{2}}=\partial\left(\frac{\partial f}{\partial L}-w\right)<0 \\
& \frac{\partial^{2} \pi}{\partial K^{2}}=\partial\left(\frac{\partial f}{\partial K}-v\right)<0
\end{aligned}
$$

From formula (23) (24), there is: 


$$
\left\{\begin{array}{l}
\partial\left(\frac{\partial f}{\partial L}\right)<0 \\
\partial\left(\frac{\partial f}{\partial K}\right)<0
\end{array}\right.
$$

In conclusion, for enterprises, they need to be encouraged to maximize the help of cultivating high-quality entrepreneurial team need so as to satisfy necessary and sufficient conditions of enterprises, which meet the formula (23) and (26) conditions.

\section{The optimal incentive model of College Students' Network Entrepreneurial Education}

Whether College Students Network entrepreneurial education can achieve high efficiency and success depends on universities. The starting point of college students' network entrepreneurial education in colleges and universities is talent cultivation, promoting the quality of personnel training (including the employment rate, the rate of entrepreneurship, the rate of professional employment counterparts, students' satisfaction on teaching index) is an important index of evaluating college teaching work and performance, which will affect the long-term development of colleges and universities. In Fig.1, through the cooperation among the school and the government, the school and enterprises, colleges expect to cultivate a certain quantity of qualified college students' network entrepreneurial teams, get higher performance scores and rankings in the teaching assessment by high authorities, so as to obtain more support from education management departments (such as fiscal appropriation); at the same time, successful college students network entrepreneurial education can promote entrepreneurship rate, employment rate, the comprehensive ranking, and other reputation for colleges, resulting in a dominant position in the organization field in the same type of universities [8], which is conducive to the sustainable development of colleges and universities

Due to the consideration of the influence of College Students' Network Entrepreneurial Education on the quality of College Talents' training, is rather difficult, the author do a further thinking from a different viewpoint: if cooperation is successful, and the influence on universities is positive, directly discuss effects of cooperative enterprises on College income under incentives, and the impact will produce certain incentives in colleges and universities. I think, for colleges, the enterprise is in pursuit of economic interests in college students' entrepreneurial education network collaboration. Universities need to maximize interests for enterprise in the process, so that they can produce a certain quantity of qualified college students' network entrepreneurial teams, gaining benefits thereby and maximizing their own interests. Based on this, the following models are proposed:

Assuming that $a$ represents the contribution degree of enterprises helping colleges and universities to cultivate a certain amount of qualified entrepreneurial teams, $B_{1}$ represents the income gained by colleges from cultivating college students' network entrepreneurial teams, $h_{1}$ stands for the income coefficient. Then there is:

$$
B_{1}=h_{1} a
$$

Enterprises' cultivation of a certain number of qualified College Student s' Network entrepreneurial team needs a certain degree of human resources, financial resources and other costs. Assuming the cost coefficient of the enterprise as $h_{2}$ and cost paid as $C_{2}$, there is:

$$
C_{2}=\frac{1}{2} h_{2} a^{2}
$$

Assuming that government policies stipulate the quantity and quality requirements for enterprises' assistance in university training of entrepreneurial teams as $g$. If this level overreached, give additional incentives while below this level rewards will be reduced. $r$ is the extra bonus amount, and $h_{3}$ is the reward coefficient for the enterprise.

$$
r=h_{3}(a-g)
$$

If $i$ is the incentive intensity for enterprises to obtain, $m$ is the cost of colleges and universities hiring good entrepreneurs, $n$ is the amount of risk loss which entrepreneurs meet in assisting universities to cultivate entrepreneurial teams to reach the demand. The income for universities is $H_{1}$, and income benefits of enterprises are $I_{1}$, then:

$$
\begin{gathered}
H_{1}=(1-i) B_{1}+i n-m \\
I_{1}=i B_{1}+r-C_{2}-i n+m
\end{gathered}
$$

Put formula (27) (28) (29) into (31), there is:

$$
I_{1}=m+\left(i h_{1}+h_{3}\right) a-\frac{1}{2} h_{2} a^{2}-i n-\mathrm{k}_{3} b
$$

As for a, there is:

$$
a=\frac{i h_{1}+h_{3}}{h_{2}}
$$

At the time when colleges cooperate with enterprises, the necessary conditions for the maximal interests of enterprises:

Put formula (27) into (30), there is:

$$
H_{1}=(1-i) \quad h_{1} a+i n-m
$$

From formula (34), we can see: 


$$
i \geq \frac{1}{h_{1}}
$$

At the point of $H_{1}$, there is the maximal interests.

From formula (33), there is:

$$
\frac{d a}{d i}=\frac{h_{1}}{h_{2}}>0
$$

As the formula (36) shows, when the enterprise incentive strength increases, the level of enterprise assisting in the training of the entrepreneurial team will be enhanced, so that universities also win a good reputation and performance and obtain the corresponding incentive.

\section{CONCLUSION}

The author thinks that, as the main body of the current college students' network education cooperation, the local government, enterprises and universities require a certain degree of incentive. Government value government performance, universities emphasize the quality of personnel training, and enterprises focus on economic benefits. The whole process of collaboration incentive is based on the cultivation of a certain quantity of qualified college students' network entrepreneurial teams. Model analysis shows that: (1) when the unit cost of the government encouraging enterprises to cultivate entrepreneurial teams is lower, the value created by the entrepreneurial team for the government is higher, so the government performance increases, and the resulting incentive is greater. (2) When the marginal revenue of human capital and other factors required for maximum profit is equal to the respective unit cost and the combination of demand factors in cultivating entrepreneurial teams achieves the best proportion, enterprises can achieve maximal profits, and obtain the corresponding incentive. (3) when the coefficient of college benefits, coefficient of enterprise incentive strength, coefficient of the government giving to the enterprise the best reward all reach maximum, the enterprise will maximize the help of cultivating entrepreneurial teams, and universities also obtain the corresponding incentive.

\section{REFERENCES}

[1] Fan Bonai,Zhang Diandian and Yu Jun, "The transformation of government functions: environment, planning, performance evaluation and implementation path based on Kast's organizational change process model", Journal of Zhejiang University (Humanities and social sciences), Vol.46, No.3 , 2016,pp.180-200.(In Chinese).

[2] Zhang Shu-tao, "The police deviation and correction of the government's performance evaluation: Based on the perspective of Intergovernmental collaborative governance", Journal of Henan Normal University (Philosophy and Social Sciences), Vol.43, No.2,2016,pp.1722. (In Chinese).

[3] Zheng Fanghui and Lu Yangfan, "Construction and the performance evaluation system of a monocracy government", Chinese Public Administration, No.6, 2014, pp.26-31. (In Chinese).

[4] Fritsch, M. and Mueller P., "The effect of new business formation on regional development over time: The case of Germany", Small Business Economics,Vol.28,2007,pp:15-29.

[5] Sungho Rho, "Economic Effect of Entrepreneurial Activity: Empirical Study on China's Economy", Unpublished doctoral Dissertation, Tsinghua University, 2012.

[6] Lee, Y. J., "Entrepreneurial Activity and Job Creation: An Empirical Evidence from Korean Regional Economy", The Korean Small Business Review, Vol. 31, No.2 2009, pp. 63-84 (in Korean)

[7] ZHAO Can, WANG Zhu-quan, YANG De-ming and CAO Wei," Research on the Catering Behavior of Enterprise and Government Subsidy Performance_Based on the Analysis of the Enterprise's Profitability", China Industrial Economics, No.7,2015,pp. 130-145. (In Chinese).

[8] Duan Jie, "Measure of Components and Drivers in Evaluating University Reputation", Higher Education Development and Evaluation, Vol.29, No.4, 2013, pp. 30-37. (In Chinese). 